\title{
HISTÓRIA: \\ DEMANDAS E DESAFIOS DO TEMPO PRESENTE - PRODUÇÃO ACADÊMICA, ENSINO DE HISTÓRIA E FORMAÇÃO DOCENTE
}

Karla Andrezza Vieira Vargas ${ }^{1}$

ARAÚJO, Raimundo Inácio Souza et al. História: demandas e desafios do tempo presente - produção acadêmica, ensino de história e formação docente. São Luís: EDUFMA, 2018.

O livro História: demandas e desafios do tempo presente - produção acadêmica, ensino de História e formação docente, é um material escrito a muitas mãos. Mãos de pesquisadores/as e professores/as, com vínculo em diferentes universidades, que tingiram em seus textos a problemática do pensar a Ciência Histórica coadunada às práticas que tangenciam a atividade do Ensino de História, na modalidade da Educação Básica, no agora. Organizada por Erinaldo Cavalcanti (professor Adjunto da Faculdade de História da Unifesspa), Geovanni Gomes Cabral (professor Adjunto da Faculdade de História da Unifesspa), Margarida Maria Dias de Oliveira (professora adjunta da UPE, Campus Nazaré da Mata) e Raimundo Inácio Souza Araújo (professor da Educação Básica, Técnica e Tecnológica do Colégio de Aplicação da Universidade Federal do Maranhão - COLUN-UFMA), a obra marca, também, as intenções do núcleo de pesquisa Interpretação do Tempo: ensino, memória, narrativa e política (iTemnpo), associado à Universidade Federal do Sul e Sudeste do Pará (Unifesspa), do qual emanou a escrita dessa coletânea.

O contexto de produção da obra está tensionado pela conjuntura política educacional, prescrita pela Reforma do Ensino Médio, que torna a matéria História optativa no currículo escolar, segundo a Lei no 13.415, de fevereiro de 2017. Assim, na apresentação, os/a organizadores/a (também autores/a), registram a importância e a funcionalidade da História em

\footnotetext{
${ }^{1}$ Professora de História da Educação Básica da rede estadual de Santa Catarina. Doutoranda em História pelo Programa de Pós-Graduação em História da Universidade do Estado de Santa Catarina.
} 
tempos de cólera. Nos textos, não encontramos resoluções acabadas, mas reflexões para um repensar de práticas que possam ser transgressoras ao universo acadêmico e as "velhas" formas de narrar a História. Fazer circular outras narrativas e outras experiências de pesquisa, segundo as proposições abordadas na obra, pode/deve contribuir para a formação de professores/as no chão da sala de aula.

A coletânea compõe treze textos, distribuídos em três eixos temáticos: História, formação docente e ensino; História, ensino e narrativas e $A$ História entre diálogos acadêmicos e o ensino. No primeiro, encontramos quatro capítulos que se articulam pela compreensão de que a História é espaço de saber e de poder, bem como expressão de formação docente. No capítulo que abre o debate, temos a escrita do professor Erinaldo Cavalcanti submetida ao título $A$ História e o ensino nas encruzilhadas do tempo: entre práticas e representações. Aqui, Cavalcanti localiza a questão da chamada História do Tempo Presente, seus sentidos e significados. Na esteia desse tempo, o autor apresenta discussões referentes aos currículos dos cursos de Licenciatura em História das Instituições de Ensino Superior Federais da Região Norte do Brasil, problematizando os usos dos livros didáticos nas práticas de ensino de egressos/as desses espaços. Margarida Dias e Itamar Freitas, no segundo capítulo, tecem considerações sobre a primeira versão da Base Nacional Comum Curricular. Construída no ano de 2015, a BNCC, previa alterações significativas do ponto de vista dos conteúdos (abertura para estudos regionais, para as questões africanas, afro-brasileiras, indígenas...), com impacto na formação e na atuação de professores/as. Base Nacional Curricular Comum: caminhos percorridos, desafios a enfrentar nomeia as reflexões dos autores.

Ainda, sobre os debates referentes à formação de professores/as de História, visualizamos no terceiro capítulo, as pesquisas de Thiago Calabria e José Batista Neto. Em Formação continuada de professores de Pernambuco para o uso das TDIC e o protagonismo dos exames estandardizados, os autores buscam analisar as ações formativas referentes às tecnologias digitais da informação e da comunicação (TDIC), nas práticas 
de ensino. Finalizando a primeira parte da obra, Maria Auxiliadora Schmidt, recupera a teoria da consciência histórica e a sua contribuição para a construção de uma matriz didática. A autora realiza um estudo sobre a Educação Histórica em vários territórios, desde o final do século XX, ancorado, especialmente, nas concepções epistemológicas de teóricos como Jörn Rüsen (2016). O texto intitula-se A teoria da consciência histórica e sua contribuição para a construção de matrizes da didática da educação histórica.

História, ensino e narrativas, segundo eixo do livro, problematiza a questão da pluralidade narrativa como um arcabouço analítico possível para se pensar o Ensino de História. Em narrativas fantásticas, ensino de História e a redescoberta da diversidade da cultura afro-maranhense, Inácio Raimundo discute a importância da construção de suportes materiais acerca da cultura afro-maranhense, atinente às prerrogativas dos marcos legais para o Ensino da História e da cultura africana, afro-brasileira e indígena Lei no 10.639/03 e Lei no 11.645/08. Na sequência, e seguindo o percurso da discussão apontada pelas demandas identitárias do tempo presente, Edson Silva, Maria da Penha e Márcio Vilela, procuram escutar as vozes das populações indígenas. Povos indígenas no ensino de História: a Lei 11.645/2008 interculturalizando o ensino fundamental avalia os efeitos, os sentidos e as apropriações dadas à temática indígena na modalidade de Ensino Fundamental.

Em A xilogravura no ensino de História: usos do passado na arte do poeta José Costa Leite, Geovanni Cabral, traz para o cenário a ideia de ampliação do corpus documental a ser potencializado na pesquisa e nas salas de aula da Educação Básica. As xilogravuras presentes em folhetos de cordel, produzidos por José Costa Leite, segundo Cabral, encontram-se carregadas de representações e visões de mundo que podem dialogar com os acontecimentos históricos nacionais e do lugar. Na dimensão da História Local, encontra-se o trabalho de Cristiani Bereta da Silva e Rosiani Marli Antônio Damásio. As autoras tomam como território o município de Garopaba (Santa Catarina) para discutir a invenção de uma tradição cultural açoriana e a sua influência no currículo escolar, a partir de 1990. Trata-se 
do título Tradição, culturas histórica e escolar: o desafio de se ensinar história local no presente. As prescrições curriculares são também preocupações de Márcio Henrique Baima Gomes em As mudanças curriculares e seus reflexos sobre o ensino de história do Maranhão (1970 a 2015). Gomes encerra a segunda parte da obra, apontando as transformações do currículo formal de História do estado do Maranhão, a sua projeção no ensino e os desafios enfrentados na sala de aula no presente.

A terceira e última parte da coletânea, A História entre diálogos acadêmicos e o ensino, encontramos o trabalho de Pablo Porfírio acerca dos diálogos discursivos entre a Guerra Fria e o movimento das Ligas Camponesas no Estado de Pernambuco. Aqui, vê-se um exercício de experimentação do objeto de pesquisa do autor e sua contribuição para o Ensino de História, intitulado Guerra fria e ligas camponesas no Brasil: outras histórias possíveis. Para além do conteúdo, este eixo incide, também, sobre estudos com impressos e suas potencialidades em práticas pedagógicas da História como disciplina escolar. A partir de $O$ que os jornais (não) dizem sobre a cidade e sua gente: uma breve proposta de ensino de história a partir dos periódicos, Thiago Santos realiza análises de relatos publicados em periódicos do XIX e suas representações discursivas, para pensar em pontes de encontro entre o que se produz na academia e o que pode encontrar terreno fértil no espaço escolar, nas aulas de História.

O trato com a memória e a questão do patrimônio cultural, são também temáticas abordadas na terceira parte do livro. Com Márcia Milena Galdez Ferreira, a partir das memórias referentes à migração de nordestinos e maranhenses para o Médio Mearim (Maranhão), pode-se refletir sobre outras agências no processo de aprendizagem histórica de estudantes. Em destaque, também, a luta pela terra, assim como bem coloca o título do capítulo Da história e memória da migração de nordestinos e maranhenses à luta pela terra no Médio Mearim, MA: proposta de mediação didática. Sobre os debates referentes ao patrimônio cultural e seu lugar na atividade de ensinar História, temos o trabalho de 
Magdalena Almeida. Em Conhecimento local e ensino de história: Reflexões sobre usos do patrimônio cultural, a autora problematiza os múltiplos objetos que constituem o patrimônio cultural do Estado de Pernambuco, bem como a construção de narrativas que se deseja veicular e significar.

A obra revela a diversidade de possibilidades da Ciência Histórica escrita nas universidades, suas conexões com o universo da Educação Básica e sua extensão na vida cotidiana. Como se vê, há um esforço de todos/as envolvidos/as na produção e circulação de narrativas plurais. Em todo o trabalho, percorrem-se as concepções do teórico Jörn Rüsen (2011) e a dimensão do sentido prático do saber histórico. Um saber comprometido com as questões do presente e do futuro. As reflexões sobre as temporalidades estão estruturadas pelas contribuições de pesquisadores como Paul Ricoeur (2012) e Reinhart Koselleck (2014). Assim, a noção de que o passado precisa/deve/pode ser desnaturalizado, tal qual postulou Durval Muniz Albuquerque Júnior (2012), é o que melhor caracteriza a organização do livro.

Da capa ao desfecho da obra o que se vê é movimento, cor, experiência, expectativa. Na imagem da capa, a ampulheta que instiga o tempo fluído pelo movimento da areia; a moldura que sugere uma janela aberta, repleta de possibilidades; as mãos que seguram a ampulheta indicam que a construção do tempo e da História é essencialmente humana. Há, portanto, um horizonte, um futuro. Sóbrio como as cores que compõem a capa e as pesquisas que dão vida ao livro. Ao final, encontramos a descrição da trajetória dos autores, elemento pontual para compreendermos inclusive as ambições desse projeto.

\section{Referências}

ALBUQUERQUE JÚNIOR, Durval Muniz de. Fazer defeitos nas memórias: para que servem o ensino e a escrita da história? In: GONÇALVES, Márcia de Almeida et al. (org.). Qual o valor da história hoje?. Rio de Janeiro: Editora FGV, 2012. p. 21-39.

KOSELLECK, Reinhart. Estratos do tempo: estudos sobre história. Rio e Janeiro: Contraponto: Editora PUC-Rio, 2014. 
RICOEUR, Paul. O passado tinha um futuro. In: MORIN, Edgar (org.). A Religação dos saberes: o desafio do século XXI. Rio de Janeiro: Bertrand Brasil, 2012.

RÜSEN, Jörn. Didática da história: passado, presente e perspectiva a partir do caso alemão. In: SCHMIDT, Maria Auxiliadora; BARCA, Isabel; MARTINS, Estevão de Rezende (org). Jörn Rüsen e o ensino de história. Curitiba: Ed. UFPR, 2011.

RÜSEN, Jörn. Contribuições para uma teoria da didática da história. Curitiba: W \& A Editores, 2016.

Recebido em 08 de janeiro de 2019

Aceito em 12 de agosto de 2019 